\title{
Depression among infertile women in Gaza strip: Prevalence and correlates
}

\section{Aymen Elsous}

Israa University

\section{Sae'd Abu El-Kass}

Al-Aqsa University

Akram Salama

Palestinian Ministry of Health

\section{Mahmoud Radwan}

Tehran university of medical science

\section{Soha Abo Eid}

Palestinian Ministry of Health

Suha Baloushah ( $\nabla$ sbaloushah@gmail.com )

Palestinian Ministry of Health https://orcid.org/0000-0002-4940-8598

\section{Research article}

Keywords: Depression, Infertility, Palestine, Prevalence, Females

Posted Date: July 2nd, 2020

DOl: https://doi.org/10.21203/rs.3.rs-36614/v1

License: (c) (i) This work is licensed under a Creative Commons Attribution 4.0 International License. Read Full License 


\section{Abstract \\ Background}

Psychological disorders are expected for women suffering from infertility. Depression is a predictable consequence and requires more investigations and considerations. This study aimed to determine prevalence and severity of depression and its predictors among infertile women in Gaza strip, Palestine using a cross-sectional design.

\section{Methods}

A cross sectional study was carried out among three hundred eighty five infertile males from Jan 2019 to Dec 2019. Participants were selected from three main In-vitro fertilization centers (IVFs) following simple random sampling. The Arabic version of Beck depression inventory was used. Logistic regression was performed to determine independent factors associated with depression. The value 0.05 or less was considered statistically significant

\section{Results}

The mean age of participated women was $29 \pm 6.58$ years, and mean duration of marriage and infertility were $7.76 \pm 5.31$ and $5.43 \pm 3.50$ years, respectively. Half of women had some form of depression $(22.3 \%$, $8.6 \%$ and $10.6 \%$ showed to have mild depression, moderate and severe depression, respectively). Predictors of depression were: duration of marriage (Wald test: 10.493 ; Cl95\%: $0.248-0.774$ ), at least one abortion (Wald test: 21.233, Cl95\%: 1.863-4.528), primary infertility (Wald test: 6.666, Cl95\%: 1.1482.742) and husband cause of infertility (Wald test: 10.878, CI95\%: 0.800-0.982).

\section{Conclusion}

Infertility has an effect on the psychological aspect of women' life. Psychological intervention including counselling, support and therapy would be necessary to limit consequences of infertility. Such interventions could be implemented in infertility treatment clinics.

\section{Background}

Infertility is inability of couples to achieve pregnancy and to have children after at least one year or more of organized sexual intercourse without protection methods(1) Infertility is not only a physical dysfunction or organ failure, and it affects all aspects of couples' life which requires further care and attention(2) . 
Infertility could be a psychological threat and one of the most important lifetime crises and social stigmatized for infertile women(3) . In Arabic cultures, infertile women may face more psychological disturbances than men because they feel accountable for inability to get pregnant or provide childbearing (4). Depression symptoms might be existed however unnoticed, and physicians usually give attention on physical part of treatment away from psychological aspect(5) .

Depressed patients have mood disorders, loss of enjoyment in routine activities, feelings of low selfesteem, anorexia, sleep disturbance, lethargy, and flight of ideas (6). Psychological researches have shown that infertility may lead to, depression or raise in symptoms if previously existed in person(7) . Begum and Hasan found high prevalence of depression among infertile individuals compared to fertile ones(8) .

The relationship between infertility and depression was reported widely (1). Infertile women showed to have much more depression when their partners suffered from impotence. Kabil and his colleagues reported $29.2 \%$ spread of depression among infertile women with impotent males compared to $4.3 \%$ among impotent males(1) .

According to the World Health Organization (WHO), approximately 60-80 million individuals have a type of infertile couples worldwide(9) . Consequently, nearly $40 \%$ of individuals who seek infertility treatment are unable to achieve pregnancy (10). In Palestine, no accurate data about prevalence of infertility among couples. However, based on the Palestinian Central Bureau of Statistics (PCBS), prevalence of infertile women in Palestine was reported to be $8.4 \%$ in the West Bank and $8.3 \%$ in Gaza Strip(11) . Infertility is a psychosocial burden for Childless women who have no history of pregnancy feel low self-esteem accompany by social pressure from their husbands, their families and husbands' families, therefore, resulting in social isolation and feeling stigmatized(12). The aim of this study was to determine the prevalence, severity of depression and explore predictors for depression among infertile women in Gaza Strip.

\section{Methods}

\section{Study design:}

This present study is a descriptive analytic cross-sectional study. The cross sectional study will help the researcher to take a snapshot over the current health problem under investigation.

\section{Study setting:}

The study was conducted at three major IFV centers in Gaza city from January to December 2019. The centers were Al-Helo, Al-Basma and Al-hindawi infertility clinic. 


\section{Study sample and sampling:}

The study was conducted among infertile women who sought IVF treatment in the above mentioned selected infertility clinics. Non-probability convenient sample was applied to select the required participants. The present study included 385 participants' women at age of $18 \mathrm{yrs}$ and older, who diagnosed as primary or secondary infertility and agreed to participate in our study voluntarily.

\section{Study Instrument}

The Arabic version of the Beck Depression Inventory (BDI) Scale was used (13) . The BDI includes 21 items in which each item describes a specific behavioral, emotional and somatic manifestation of depression. The BDI items cover sadness, pessimism, sense of failure, dissatisfaction, guilt, expectation of punishment, self-dislike, self-accusations, suicidal ideas, crying, irritability, social withdrawal, indecisiveness, body image change, work retardation, insomnia, fatigability, anorexia, weight loss, somatic preoccupation and loss of libido(14). The score of the BDI is based on 4 point Likert scale. It ranges from " 0 " that indicates no depression, to " 4 " for severe depression. Therefore, the overall scale score ranges from 0-63. The BDI scores are classified as no depression (score 0-13), mild (14-19), moderate (20-28), and severe (29-63) (15). Socio-demographic and infertility history data including age, residency, education, employment, duration of marriage, polygamy husband, type of infertility, duration of infertility, IVF times, and infertility cause were also gathered.

\section{Data collection}

Data was gathered through exit, face to face based interviews. Pilot interviews were conducted with 20 infertile female patients to ensure clarity of questions. Results of the pilot were excluded from the final data collection. Three well trained data collectors were recruited to gather the data from the eligible infertile women in the three IVF centers.

\section{Data collection and Analysis}

Data were analyzed using the Statistical Package for Social Sciences Software Version 22. Continuous variables were presented informs of mean and standard deviation. Frequency and percentage were presented for categorical variables. Bivariate analysis was conducted to select independent variables for multivariate logistic regression. We aimed to take wide number of independent variables, and therefore independent variables with $\mathrm{p}<.250$ were chosen accordingly because the frequently used $P \leq .05$ usually fails to capture significant variables (16). Multivariate regression analysis for potential predictors of depression in infertile women was performed and $p \leq .05$ was considered statistically significant. 


\section{Results}

\section{Characteristics of study participants}

Three hundred eighty five infertile women participated. The women's mean age \pm SD was $29 \pm 6.58$ years, duration of marriage $7.76 \pm 5.31$ years, IVF trial times $1.82 \pm 1.88$ and duration of infertility $5.43 \pm 3.50$ years. Sixty percent $(227 / 385)$ completed at least university level.

The majority were housewives (78.4\%) and $34.3 \%$ of women infertility was related to their husbands. Socio-demographic and Obst/Gyn characteristics of the study participants are summarized in Table 1.

\section{Severity of depression}

According to $\mathrm{BDI}, 50.6 \%$ had some form of depression. Of which $22.3 \%(86 / 350)$ showed to have mild depression, $8.6 \%$ (33/350) and 10.6\% (41/350) had moderate and severe depression, respectively. Around half of women $(49.4 \%)$ showed no symptom of depression.

\section{Independent factors and severity of depression}

The mean score of depression increased when level of education improved. Depression increased with higher education although there was no statistical significance $(P=0.271)$. Duration of marriage $(p<$ $0.001)$ and type of infertility $(p<0.05)$ tend to have influence on the emotional status. Longer marital years and primary infertility have positive influence on occurrence of depression. Moreover, depression increased when infertility cause was linked to husbands or unknown cause $(p<.012)$. Frequency of depression increased when duration of infertility is less than 5 years, however, it is not significant $(p=$ .985). Depression is more among women who experienced at least two IVFs attempts $(P>0.5)$. Unemployed women reported more depression than employed women but it is not significant $(P=.981)$ (Table 2).

\section{Logistic regressions for potential correlates of depression in infertile women}

Among the variables in the model, duration of marriage (> 6 years) (Wald test: 10.493; Cl95\%: 0.248 $0.774 ; \mathrm{P}=.001$ ), at least one abortion (Wald test: 21.233 , Cl95\%: $1.863-4.528 ; \mathrm{p}<.0001$ ), primary infertility (Wald test: 6.666, Cl95\%: $1.148-2.742 ; \mathrm{p}=.01$ ) and husband cause of infertility (Wald test: 10.878, Cl95\%: $0.800-0.982 ; \mathrm{p}<.05$ ) were predictors for depression of infertile women (Table 3 )

\section{Discussion}


This study was conducted to determine the distribution of depression among infertile females. According to our society's norms and culture, having a child is an important issue in marital life and inability to have it would create challenges for infertile couples, particularly females. Infertile females are deprived of their important maternal role and are ultimately threatened by psychological disorders. To the best of our knowledge, this is the first study addresses a psychological disorder, depression, in infertile women. A growing body of evidence emphasized on psychological aspect of infertility in women $(1,6,10,17-23)$. Infertility is a source of stress for couples who are unable to conceive and depression was most commonly reported and its incidence varied among societies and countries. However, a study found occurrence of depression in infertile individuals is no more common than in entire population (24). The Depression Beck Inventory is a screening tool characterized by good sensitivity but low specificity.

In our study, $50.6 \%$ of infertile women had some form of depression. This finding is similar to reports from Nigeria and Saudi Arabia $(6,22)$ which was $52.7 \%$ and $53.8 \%$, respectively. Other studies found lower prevalence $(25,26)$. Differences in prevalence rate could be attributed to using various instruments to assess depression. Some have used the Patient Health Questionnaire, the Beck's Depression Inventory $(\mathrm{BDI})$, the General Health Questionnaire (GHQ) or the Hospital Anxiety and Depression Scale (HADS).

Husband infertility was a significant predictor for depression in women. This is in line to previous studies $(18,27-29)$. Men in Middle Eastern countries practice their family role as powerful virile by means of reproduction, thus infertility is challenging and threatening problem which may result in psychological distress to their counterparts women. These psychological distresses are displacing to women because they are the submissive and dependent on males. Males' infertility may also result in low sexual selfesteem and performance and if emotional connection, in terms of sexual intercourse, is failed to achieve its purpose, couples might be divided or isolated. Thus, women remain under stress for prolong duration. Savadzadeh and Madadzadeh (29) stated if males' capabilities failed to get their partners pregnant, a devastating emotional sequence, including depression, is expected for couples however is much more among wives. By and large, male infertility factors lead to psychological burden for both men and women; however, it is much more in women(30) .

Duration of infertility was not a predictor for depression. This is in line with findings from Iran $(19,27)$, Nigeria(26) and Japan (31). In return, infertility duration showed to have effect on occurrence of depression in first three years of infertility, however, depression subsequently decreased with time (32). Possible explanation could be attributed to adjustment of infertile women to infertility, sharing problem with medical professionals and the hope for successful trials in accordance with new technologies and techniques which give hope for pregnancy. Moreover, the desensitization model presented by Kopitzke et al.,(33) could also be applied. The model describes individual's stress response to initial diagnosis and his/her coping with prolong exposure to stressful situations and become desensitized.

In our study, we found no significant relationship between age and depression. In line to studies' findings (21), female age was not a predictor for occurrence of depression. This is in contrast to Alhassan, Ziblim and Muntaka(17), Al-Homaidan (6) and Awoyinka and Ohaeri (34) reports from Ghana, Saudi Arabia and 
Nigeria, respectively. We do speculate that young females expose to psychological and social pressure similar to their older counterparts which hide age related symptoms of depression.

Duration of marriage was a significant predictor for depression similar to previous studies $(24,25)$. However, this is not in line with Oladeji and OlaOlorun,(21). Possible explanation could be attributed to different geographical locations and societies that held different beliefs and norms and to social or partner support.

Abortion was found to be a significant predictor for depression among infertile women. This result is in agreement with findings of Kolte et al., (35), Zamani et al., (36) and Adib-Rad et al., (37). Similarly, Kagami et al., (38) used the Beck Depression index and found significant higher levels of depression among women as compared with men. Recurrent abortion is a serious point for infertile women and it is not easy to cope or recover spontaneously. For sure, they require kind of support, care and interventions to help them to adjust after pregnancy loss. Moreover, we think that infertile women after spontaneous abortion lose hope to become mothers and thus may produce source of internal psychological pressure and guilty feeling.

Type of infertility is another predictor of depression in our present study. This result is similar to the previous publishes result from survey about depression among infertile women in Ghana (17), Saudi Arabia(39) and in Iraq (40). Having a child is very important to the Palestinian community. Childbearing women have higher marital satisfaction and social value among her family members. Being unable to conceive add psychosocial burden over the infertile woman life. Infertility affects the infertile women marriage stability and psychological well-being as it proven in our research result.

The study has many limitations; firstly, the study approached only infertile females who seek IVF treatment, however, there were still infertile women who are economically unaffordable to seek treatment and we belief that depression could be much higher. We do recommend further studies on this part of population. Secondly, the conservative culture of Palestinian community makes it hard sometimes to ask questions about infertility and sexual function. Thirdly, the nature of cross-sectional design limits establishment of causal inferences with study variables. Fourthly, using of self-rating questionnaire limited the in-depth exploration of psychological distresses, depression. The advantage of the study is that findings reflect the characteristics of general population in infertile women because most famous infertility treatment clinics, including the selected center in our study, are located in Gaza city.

\section{Conclusion}

Infertility affects different aspects of peoples' life including psychological part. Symptoms of depression are presented in half of infertile females. Females' age, duration of infertility and IVFs attempts are not predictors for depression. However, duration of marriage, abortion times, and male factor infertility are predictors with high significance. Ignorance of psychological aspects of infertility may threaten continuity of couples' marriage and prolong treatment courses. Thus, psychological intervention including counselling, support and therapy would be necessary to prevent or overcome the implications of 
infertility. Such interventions could be implemented in infertility treatment centers or through nongovernmental organizations.

\section{Abbreviations}

- BDI: Beck Depression Inventory

- Cl: Confidence Interval

- GHQ: General Health Questionnaire

- HADS: hospital Anxiety and Depression Scale

- IVF: Invitro Fertilization

- PCBS: Palestinian central Bureaux o Statistics

- SD: standard deviation

- WHO: World Health Organization

\section{Declarations}

\section{Ethics approval and consent to participate:}

The study approved from the Palestinian health research counseling, HELSINKI committee (PHRC/HC/277/17). Also, the invited participant signed on consent form before their participations

Consent for publication:

Not applicable.

\section{Availability of data and material}

Data are available upon request made to corresponding author

\section{Competing of interest}

The research has no conflict of interest.

\section{Funding}

None

\section{Author's contribution}

$S B$ and $A E$ designed the study. Data analysis was performed by $A E$. AE, SK and AS wrote the first draft. $S B, A E$, SK and AS edited the manuscript and approved it before submission. All authors have read and approved the manuscript. 


\section{Acknowledgment}

The authors are grateful to head of infertility clinics for their permission to act the study. We are also thankful to women who agreed to participate. Many thanks for the midwifes who collected the data

\section{References}

1. Ozturk S, Sut HK, Kucuk L. Examination of sexual functions and depressive symptoms among infertile and fertile women. Pakistan journal of medical sciences. 2019;35(5):1355.

2. Ramezanzadeh F, Noorbala A-A, Abedinia N, Forooshani AR, Naghizadeh MM. Psychiatric intervention improved pregnancy rates in infertile couples. The Malaysian journal of medical sciences: MJMS. 2011;18(1):16.

3. Karlidere T, Bozkurt A, Ozmenler KN, Ozsahin A, Kucuk T, Yetkin S. The influence of emotional distress on the outcome of in-vitro fertilization (IVF) and/or intracytoplasmic sperm injection (ICSI) treatment among infertile Turkish women. Isr J Psychiatry Relat Sci. 2008;45(1):55.

4. Wiersema NJ, Drukker AJ, Dung MBT, Nhu GH, Nhu NT, Lambalk CB. Consequences of infertility in developing countries: results of a questionnaire and interview survey in the South of Vietnam. Journal of Translational Medicine. 2006;4(1):54.

5. Zare Z, Amirian M, Golmakani N, Mazlom R, Ahangar ML. Sexual dysfunction in infertile women. International Journal of Reproductive BioMedicine. 2016;14(2):89.

6. Al-Homaidan HT. Depression among women with primary infertility attending an infertility clinic in Riyadh, Kingdom of Saudi Arabia: rate, severity, and contributing factors. International journal of health sciences. 2011;5(2):108.

7. Lawson AK, Klock SC, Pavone ME, Hirshfeld-Cytron J, Smith KN, Kazer RR. Prospective study of depression and anxiety in female fertility preservation and infertility patients. Fertility sterility. 2014;102(5):1377-84.

8. Begum BN, Hasan S. Psychological problems among women with infertility problem: a comparative study. J Pak Med Assoc. 2014;64(11):1287-91.

9. Sirdah MM, Abushahla AK, Ghalayeni BY, Aburamadan AG. Etiological risk factors for subfertility among Palestinian women in Gaza. Journal of biomedical research. 2013;27(2):127.

10. Shahraki Z, Tanha FD, Ghajarzadeh M. Depression, sexual dysfunction and sexual quality of life in women with infertility. BMC Womens Health. 2018;18(1):92.

11. (PCBS) PCBoS. Issues the results of the Family Survey 2010. 2010.

12. Nahar P, Richters A. Suffering of childless women in Bangladesh: the intersection of social identities of gender and class. Anthropol Med. 2011;18(3):327-38.

13. AG. G. Manual of the Arabic BDI-II.. Cairo, Egypt: 2000.

14. McDowell INC. A Guide to Rating Scales and Questionnaires.. Second edition. Textbook of Measuring Health ed2006. 
15. Beck ATSR. Brown GK.. BDI-II Manual.. 1966.

16. Mickey RGS. The impact of confounder selection criteria on effect estimation.. Am J Epidemiol $1989 ; 129(125)$.

17. Alhassan A, Ziblim AR, Muntaka S. A survey on depression among infertile women in Ghana. BMC Womens Health. 2014;14(1):42.

18. Farzadi L, Ghasemzadeh A. Two main independent predictors of depression among infertile women: an Asian experience. Taiwanese journal of obstetrics gynecology. 2008;47(2):163-7.

19. Mohammadpour A, Ghodrati M. The Prevalence and Severity of Depression and its Correlation with Demographic Characteristics in Infertile Females Referred to Mashhad Milad Center. Jundishapur Journal of Chronic Disease Care. 2018;7(2).

20. Sezgin H, Hocaoglu C, Guvendag-Guven ES. Disability, psychiatric symptoms, and quality of life in infertile women: a cross-sectional study in Turkey. Shanghai archives of psychiatry. 2016;28(2):86.

21. Oladeji S, OlaOlorun A. Depression among infertile women in Ogbomosoland. South African Family Practice. 2018;60(2):41-5.

22. Brasile D, Katsoff B, Check J. Moderate or severe depression is uncommon in women seeking infertility therapy according to the beck depression inventory. Clin Exp Obstet Gynecol. 2006;33(1):16-8.

23. Drosdzol A, Skrzypulec V. Depression and anxiety among Polish infertile couples-an evaluative prevalence study. Journal of psychosomatic obstetrics gynaecology. 2009 Mar;30(1):11-20. PubMed PMID: 19308778. Epub 2009/03/25. eng.

24. Ikeako L, Iteke O, Ezegwui H, Okeke T. Clinico-demographic indicators of depression among infertile women in a tertiary health institution in Awka, South East Nigeria. Journal of Advances in Medicine and Medical Research. 2015:921-31.

25. Upkong D, Orgi E. Mental health of infertile women in Nigeria. 2006.

26. Ramezanzadeh F, Aghssa MM, Abedinia N, Zayeri F, Khanafshar N, Shariat M, et al. A survey of relationship between anxiety, depression and duration of infertility. BMC Womens Health. 2004;4(1):9.

27. Sheiner E, Sheiner E, Potashnik G, Carel R, Shoham-Vardi I. The relationship between occupational psychological stress and female fertility. Occup Med. 2003;53(4):265-9.

28. Vo TM, Tran QT, Le CV, Do TT, Le TM. Depression and associated factors among infertile women at Tu Du hospital, Vietnam: a cross-sectional study. International Journal of Women's Health. 2019;11:343.

29. Savadzadeh s, Madadzadeh N. Explanation of emotional feelings of women with infertility: a qualitative study. 2013.

30. Dyer SJ, Abrahams N, Mokoena N, van der Spuy ZM. 'You are a man because you have children': experiences, reproductive health knowledge and treatment-seeking behaviour among men suffering from couple infertility in South Africa. Hum Reprod. 2004;19(4):960-7. 
31. Kee BS, Jung BJ, Lee SH. A study on psychological strain in IVF patients. J Assist Reprod Genet. 2000 Sep;17(8):445-8. PubMed PMID: 11062855. Pubmed Central PMCID: PMC3455575. Epub 2000/11/04. eng.

32. Matsubayashi H, Hosaka T, Izumi S-i, Suzuki T, Kondo A, Makino T. Increased depression and anxiety in infertile Japanese women resulting from lack of husband's support and feelings of stress. Gen Hosp Psychiatry. 2004;26(5):398-404.

33. Kopitzke EJ, Berg BJ, Wilson JF, Owens D. Physical and emotional stress associated with components of the infertility investigation: perspectives of professionals and patients. Fertility sterility. 1991;55(6):1137-43.

34. Awoyinka MF, Ohaeri BM. Depression and coping strategies among women with infertility, attending three gynaecological clinics in Ibadan. Journal of Medicine Biomedical Research. 2014;13(2):48-60.

35. Kolte A, Olsen LR, Mikkelsen E, Christiansen O, Nielsen HS. Depression and emotional stress is highly prevalent among women with recurrent pregnancy loss. Human reproduction. 2015;30(4):777-82.

36. Zamani N, Ghasemi M, Jokar E, Khazri Moghadam N. Comparison of depression and life quality of fertile and infertile women and those with frequent abortions. Journal of Babol University of Medical Sciences. 2013;15(6):78-83.

37. Adib-Rad H, Basirat Z, Faramarzi M, Mostafazadeh A, Bijani A. Psychological distress in women with recurrent spontaneous abortion: A case-control study. Turkish journal of obstetrics gynecology. 2019;16(3):151.

38. Kagami M, Maruyama T, Koizumi T, Miyazaki K, Nishikawa-Uchida S, Oda H, et al. Psychological adjustment and psychosocial stress among Japanese couples with a history of recurrent pregnancy loss. Human reproduction. 2012;27(3):787-94.

39. Al-Homaidan HT. Depression among Women with Primary Infertility attending an Infertility Clinic in Riyadh, Kingdom of Saudi Arabia: Rate, Severity, and Contributing Factors. Int J Health Sci (Qassim). 2011 Jul;5(2):108-15. PubMed PMID: 23267288. Pubmed Central PMCID: PMC3521829. Epub 2011/07/01. eng.

40. Al-Asadi JN, Hussein ZB. Depression among infertile women in Basrah, Iraq: Prevalence and risk factors. Journal of the Chinese medical association. 2015;78(11):673-7.

\section{Tables}

Table 1: Baseline characteristics of participated women: 


\begin{tabular}{|c|c|c|c|}
\hline Serial & Variable & $\mathrm{n}$ & $\%$ \\
\hline 1 & Age (M \pm SD: $29 \pm 6.58)$ & & \\
\hline & $\leq 30$ years & 254 & 66.0 \\
\hline 2 & $\begin{array}{l}>30 \\
\text { Living place }\end{array}$ & 131 & 34.0 \\
\hline & North & 72 & 18.7 \\
\hline & Gaza & 182 & 47.3 \\
\hline & Middle area & 62 & 16.1 \\
\hline & South & 69 & 17.9 \\
\hline 3 & Education & & \\
\hline & Illiterate & 25 & 6.5 \\
\hline & Up to sec. school & 133 & 34.5 \\
\hline 4 & $\begin{array}{l}\quad \geq \text { university } \\
\text { Employment }\end{array}$ & 227 & 59.0 \\
\hline & Have job & 83 & 21.6 \\
\hline 5 & $\begin{array}{l}\text { Housewife } \\
\text { Duration of marriage }\end{array}$ & 302 & 78.4 \\
\hline & $(\mathrm{M} \pm \mathrm{SD}: \quad 7.76 \pm 5.31)$ & & \\
\hline & $\leq 6$ years & 188 & 48.8 \\
\hline 6 & $\begin{array}{l}>6 \\
\text { Polygamy husband }\end{array}$ & 197 & 51.2 \\
\hline & Yes & 47 & 12.2 \\
\hline 7 & $\begin{array}{l}\text { No } \\
\text { Type of infertility }\end{array}$ & 338 & 87.8 \\
\hline & Primary & 242 & 62.9 \\
\hline 8 & $\begin{array}{l}\text { Secondary } \\
\text { Duration of infertility }\end{array}$ & 143 & 37.1 \\
\hline & $(\mathrm{M} \pm \mathrm{SD}: 5.43 \pm 3.50)$ & & \\
\hline & $\leq 5$ years & 219 & 56.9 \\
\hline 9 & $\begin{array}{l}\quad>5 \\
\text { IVF times (M } \pm \text { SD: } 1.82 \pm 1.88)\end{array}$ & 162 & 42.1 \\
\hline & $\leq 2$ times & 274 & 71.2 \\
\hline 10 & $\begin{array}{l}>2 \\
\text { No. abortion (M } \pm \text { SD: } 0.74 \pm 1.31)\end{array}$ & 106 & 27.5 \\
\hline & Zero & 249 & 64.7 \\
\hline
\end{tabular}




$\begin{array}{lll}\geq 11 \quad \text { Infertility cause } & 136 & 35.3 \\ \text { Wife cause } & 54 & 14.0 \\ \text { Husband cause } & 132 & 34.3 \\ \text { Both } & 78 & 20.3 \\ \text { Unknown } & 121 & 31.4\end{array}$

Table 2: Distribution of depressed women with regard to independent variables 


\begin{tabular}{|c|c|c|c|c|c|c|}
\hline \multirow[t]{2}{*}{ Serial } & \multirow[t]{2}{*}{ Variables } & \multicolumn{5}{|c|}{ Level of depression } \\
\hline & & $\begin{array}{c}\text { No } \\
\text { depression }\end{array}$ & $\begin{array}{c}\text { Mild } \\
\text { depression } \\
\end{array}$ & $\begin{array}{c}\text { Moderate } \\
\text { depression }\end{array}$ & $\begin{array}{c}\text { Severe } \\
\text { depression }\end{array}$ & $\mathbf{P}$ \\
\hline \multirow[t]{2}{*}{1} & Age & & & & & \\
\hline & $\leq 30$ years & 131 & 58 & 15 & 25 & .061 \\
\hline \multirow{5}{*}{2} & $>30$ & 59 & 28 & 18 & 16 & \\
\hline & North & 38 & 13 & 8 & 6 & \\
\hline & Gaza & 91 & 44 & 9 & 20 & .278 \\
\hline & Middle area & 25 & 14 & 10 & 9 & \\
\hline & South & 36 & 15 & 6 & 6 & \\
\hline \multirow[t]{4}{*}{3} & Education & & & & & \\
\hline & Illiterate & 6 & 8 & 4 & 4 & \\
\hline & Up to sec. school & 64 & 28 & 9 & 14 & .271 \\
\hline & $\geq$ university & 120 & 50 & 20 & 23 & \\
\hline \multirow[t]{4}{*}{4} & $\begin{array}{l}\text { Duration of } \\
\text { marriage }\end{array}$ & & & & & \\
\hline & - G- & 108 & 39 & 14 & 10 & .001 \\
\hline & $=0$ years & 82 & 47 & 19 & 31 & \\
\hline & $>6$ & & & & & \\
\hline \multirow[t]{3}{*}{5} & Polygamy husband & & & & & \\
\hline & Yes & 21 & 9 & 4 & 7 & .716 \\
\hline & No & 169 & 77 & 29 & 34 & \\
\hline \multirow[t]{4}{*}{6} & $\begin{array}{l}\text { Duration of } \\
\text { infertility }\end{array}$ & & & & & \\
\hline & 5 & 107 & 50 & 18 & 24 & .985 \\
\hline & & 79 & 36 & 15 & 17 & \\
\hline & $>5$ & & & & & \\
\hline \multirow{3}{*}{7} & & & & & & \\
\hline & $>2$ times & 142 & 64 & 22 & 22 & .055 \\
\hline & $\leq 2$ & 46 & 22 & 11 & 18 & \\
\hline \multirow[t]{5}{*}{8} & Infertility cause & & & & & \\
\hline & Wife cause & 21 & 18 & 5 & 6 & \\
\hline & Husband cause & 31 & 27 & 8 & 6 & .012 \\
\hline & Both & 30 & 19 & 10 & 11 & \\
\hline & Unknown & 58 & 22 & 10 & 18 & \\
\hline
\end{tabular}




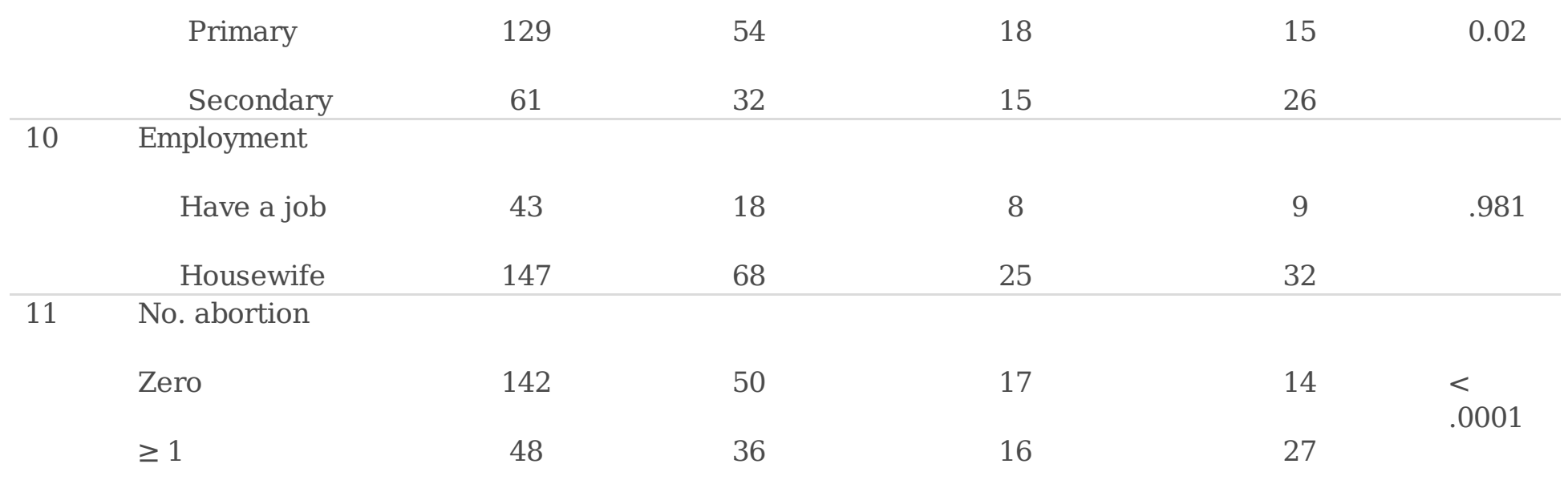

Table 3: Multivariate regression analysis for potential correlates of depression in infertile females 


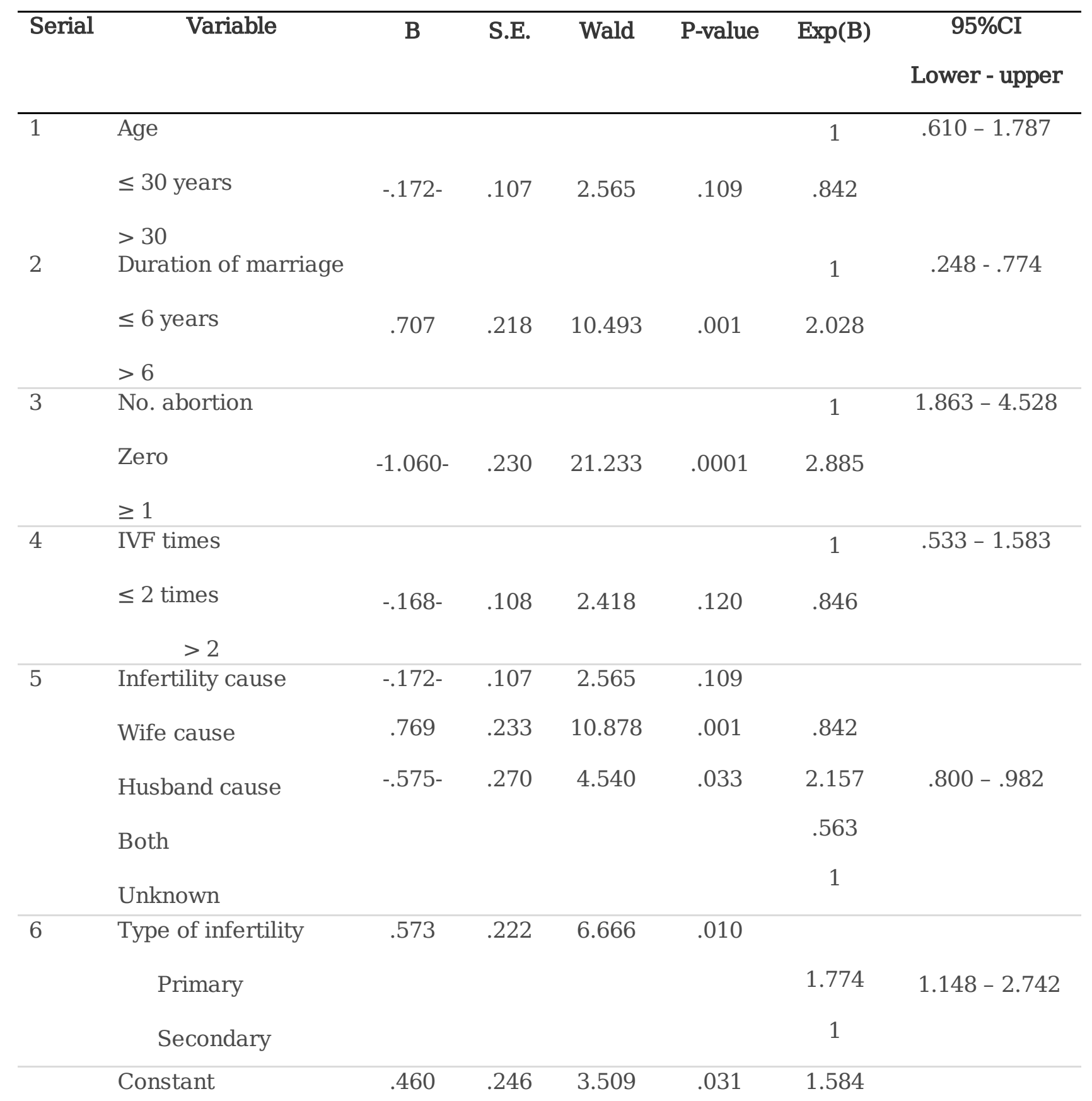

\section{Supplementary Files}

This is a list of supplementary files associated with this preprint. Click to download.

- STROBEchecklistcrosssectional.doc 